\title{
Silencing VEGF enhances the radiosensitivity of the radioresistant human nasopharyngeal carcinoma cell line CNE-2R by inhibiting autophagy through the activation of mTOR pathway
}

\section{Li Chen}

Guangxi Cancer Hospital and Guangxi Medical University Affiliated Cancer Hospital

\section{Guoxiang Lin}

Guangxi Cancer Hospital and Guangxi Medical University Affiliated Cancer Hospital Kaihua Chen

Guangxi Cancer Hospital and Guangxi Medical University Affiliated Cancer Hospital Fangzhu Wan

Guangxi Cancer Hospital and Guangxi Medical University Affiliated Cancer Hospital

\section{Yongchu Sun}

Guangxi Cancer Hospital and Guangxi Medical University Affiliated Cancer Hospital

\section{Renba Liang}

Guangxi Cancer Hospital and Guangxi Medical University Affiliated Cancer Hospital

\section{Xishan Chen}

Guangxi Cancer Hospital and Guangxi Medical University Affiliated Cancer Hospital

Xiaodong Zhu ( $\nabla$ zhuxdonggxmu@126.com )

Guangxi Cancer Hospital and Guangxi Medical University Affiliated Cancer Hospital https://orcid.org/0000-0002-7997-8268

\section{Research article}

Keywords: nasopharyngeal carcinoma, VEGF, radiosensitivity, autophagy, mTOR

Posted Date: May 11th, 2020

DOl: https://doi.org/10.21203/rs.3.rs-26678/v1

License: (c) (1) This work is licensed under a Creative Commons Attribution 4.0 International License. Read Full License 


\section{Abstract}

Background: Vascular endothelial growth factor (VEGF) is an important pro-angiogenic factor. VEGF was reported to promote the occurrence of autophagy, which enhanced to the radioresistance of tumors. The purpose of our study was to investigate the influence of VEGF silencing on the radiosensitivity of nasopharyngeal carcinoma radioresistant cell line CNE-2R and the underlying mechanisms.

Methods: The radiosensitivity of CNE-2R cells after silencing VEGF was detected by cell counting kit 8 (CCK-8) and clonogenic assay, cell cycle and apoptosis was subjected to flow cytometry. DNA damage and autophagy were observed by immunofluorescence and western blotting. The interaction between VEGF and mTOR was confirmed by western blotting and co-immunoprecipitation analysis. In vivo, the effect of VEGF on radiosensitivity of NPC cells was investigated through xenograft model, furthermore, immunohistochemistry and TUNEL assay were used to further verify the relationship between autophagy and radiosensitivity in NPC after VEGF depletion.

Results: Downregulation of VEGF significantly inhibited cell proliferation and induced apoptosis of CNE$2 \mathrm{R}$ cells after radiotherapy in vitro and in vivo. In addition, VEGF knockdown not only decreased autophagy level, but also delayed the DNA damage repair in CNE-2R cells after irradiation. Mechanistically, silencing VEGF suppressed autophagy through the activation of mTOR pathway.

Conclusion: VEGF depletion increased radiosensitivity of NPC radioresistant cell CNE-2R by suppressing autophagy via the activation of mTOR pathway.

\section{Introduction}

Nasopharyngeal carcinoma (NPC) is a common tumor dominant in Southeast Asia especially in southern China, with an annual incidence of about 20 cases per 100,000 people [1]. NPC is characterized by poor tumor differentiation, complex anatomical location, rapid invasion of adjacent organs However, about $20 \%$ of patients with NPC develop local recurrence and distant metastasis after standard therapy due to radioresistance [2]. Therefore, exploring the factors that cause radioresistance of NPC and the underlying molecular mechanisms is important for improving the treatment efficacy and prognosis of NPC patients.

Autophagy is a conserved and essential process in organisms [3], in which unwanted cellular contents are cleared by lysosomal degradation to maintain cell survival during stress responses [4]. Its function of scavenging intracellular waste is also one of the important mechanisms by which it inhibits tumor growth [5]. Autophagy is thought to contribute to tumor radioresistance [6,7]. Our previous studies demonstrated inhibition of autophagy enhances radiosensitivity of NPC cells[8], which was also corroborated by Chu's report [9].

Vascular endothelial growth factor (VEGF) is an important pro-angiogenic factor that promotes tumor angiogenesis. VEGF causes tumor cell reoxygenation, which leads to 
excessive DNA replication, increased synthesis of radioresistance genes, and radioresistance [10]. Hu [11] showed that radioresistance in esophageal cancer was associated with radiation-induced abnormal secretion of VEGF, which protected tumor vessels from radiation-related damage and subsequently increased the radioresistance of tumors. In addition, VEGF inhibited autophagy process, as evidenced by the finding that the autophagic flux and cell activity decreased significantly in VEGF-silenced tumor cells [12].

Mammalian target of rapamycin (mTOR) is a receptor for amino acids, ATP and hormones [13]. Increasing evidence have demonstrated that mTOR inhibition activate the occurence of autophagy [14]. Furthermore, studies have indicated VEGF is involved in the regulation of the mTOR pathway[15-16]. However, whether VEGF regulates autophagy and affects radiosensitivity of NPC through mTOR signaling pathway has not yet been clarified.

We have constructed the NPC radioresistant cell line CNE-2R in vitro by fractional induction of radiation on CNE-2 cells [17], and we found that inhibition of autophagy enhanced radiosensitivity of CNE-2R cells [18]. In our study, we assessed the biological function of VEGF on radiosensitivity of CNE-2R cells. In vitro and in vivo assays indicated that VEGF knockdown inhibited cell proliferation, facilitated cell apoptosis and enhanced the radiosensitivity of NPC cells. We also found that Downregulation of VEGF repressed autophagy through the activation of mTOR pathway. Our study reveal that the molecular regulatory mechanism of VEGF, which could also be a prognostic biomarker in NPC.

\section{Materials And Methods}

\section{Cell lines and transfection}

In our previous studies, we had established radiation-tolerant CNE-2R cells. Cells were maintained in RPMI-1640 (Gibco, Grand Island, NY, USA) medium containing 10\% fetal bovine serum (FBS, Gibco, Grand Island, NY, USA) at $37^{\circ} \mathrm{C}$ in $5 \% \mathrm{CO}_{2}$ incubator. The GV248-Puromycin-EGFP-shRNA-VEGF lentiviral vectors and GV358-3FLAG- Puromycin-EGFP-VEGF lentiviral vectors (Genechem, Shanghai, China) were transfected into CNE-2R cells. The transfection effect was verified by QPCR and western blotting. The molecular sequence of VEGF was obtained in GenBank (No.NM_001171626).

\section{RT-qPCR analysis}

Total RNA was isolated from cells with TRIzol reagent (Takara, Dalian, Japan), and then reversetranscribed into cDNA. The SYBR ${ }^{\circledR}$ Premix Ex Taq ${ }^{\mathrm{TM}}$ II (Takara, Dalian, Japan), $\mathrm{dH}_{2} \mathrm{O}, \mathrm{cDNA}$, and primers were mixed to prepare a qPCR reaction system, and a RT-qPCR reaction was performed. The relative quantitative analysis of mRNA was conducted by the $2^{-\triangle \Delta c t}$ method. The primers were as follows: $\left(5^{\prime} \rightarrow 3^{\prime}\right)$ : VEGF-F: TCACAGGTACAGGGATGAGGACAC, VEGF-R: CAAAGCACAGCAATGTCCTGAAG; GAPDHF:CAGGAGGCATTGCTGATGAT, GAPDH-R: GAAGGCTGGGGCTCATTT.

\section{Western blot analysis}


Total protein was isolated from cells by RIPA (Beyotime, Shanghai, China) protein lysate. Quantitative detection of protein was conducted by the BCA (Beyotime, Shanghai, China) method. Thereafter, $20 \mu \mathrm{g}$ of protein sample was added to appropriate amount of $4 \times$ loading buffer and denatured by heating. After electrophoresis by SDS-PAGE (6\%-12\%), the proteins were then transferred to PVDF membranes and blocked with $5 \%$ skimmed milk. The corresponding primary and secondary antibodies were incubated with the membranes. The bands were exposed with ECL chemiluminescence and analyzed with gel imaging system.

\section{Clonogenic Assay}

Cells at densities of $200,200,400,600,1000$ cells/well were added to a six-well plate according to the 0 , 2, 4, 6 and 8 Gy irradiation doses. After 24 hours of culture, cells were subjected to different irradiation with $6 \mathrm{MV}$ X-rays, and then cultured for 2 weeks. The medium was discarded, and the cells were fixed with $4 \%$ paraformaldehyde (Solarbio, Beijing, China) and stained with Giemsa stain (Solarbioo, Beijing, China). More than 50 cells were considered to be an effective colony, and the relevant parameters were calculated, clonal formation rate $(\mathrm{PE})$ = number of effective colonies / number of cells inoculated, survival fraction (SF) = PE of irradiated cells / PE of non-irradiated cells. Based on the multi-target model, we fitted the cell survival curve by using the GraphPad Prism 5.0 software, and $D_{0}(=1 / k), D q\left(=\ln N\right.$ * $\left.D_{0}\right)$ and $\mathrm{SF}_{2}$ were calculated.

\section{Cell Counting Kit 8}

Cell suspensions at $4 \times 10^{3}$ cells/well were added to 96 -well plates. After incubating for 24 hours, the cells were subjected to different irradiation with $6 \mathrm{MV}$ X-rays and then cultured for another 48 hours. After that, adding $10 \mu \mathrm{L}$ of CCK-8 (Dojindo, Shanghai, China) for every $100 \mu \mathrm{L}$ medium and incubating for $1 \mathrm{~h}$. The microplate reader (Thermo Fisher, USA) was used to measure the absorbance value of each group at 450 $\mathrm{nm}$ and the SF of cell was calculated.

\section{Cell Cycle Analysis}

After all groups of cells were irradiated with $0 \mathrm{~Gy}$ or $8 \mathrm{~Gy}$ with $6 \mathrm{MV}$ X-rays for 48 hours, $5 \times 10^{5}$ cells were collected from each group and washed with PBS. Each group was fixed with $1 \mathrm{~mL}$ of $75 \%$ pre-cooled ethanol at $-20^{\circ} \mathrm{C}$ overnight, and washed with PBS. Then, $0.5 \mathrm{~mL}$ PI/RNA staining buffer (BD, New Jersey, USA) was added for $20 \mathrm{~min}$. All cells were filtered with a nylon filter and detected by flow cytometer .

\section{Apoptosis Analysis}

After all groups of cells were were rradiated with 0 Gy or 8 Gy with $6 \mathrm{MV} \mathrm{X-rays} \mathrm{for} 48$ hours, $5 \times 10^{5}$ cells were collected from each group and washed with PBS. After that, cell suspension were added $7 \mu \mathrm{L}$ Annexin V-APC /7-AAD (BD, New Jersey, USA) for 20 min. Thereafter, the cells were filtered with a nylon filter and detected by flow cytometer (BD, New Jersey, USA). 


\section{Immunofluorescence}

The two groups of cell suspensions were inoculated on coverslips, and they were irradiated with $8 \mathrm{~Gy}$ irradiation after 24 hours of culture. At indicated time points $(1,3,6,12$ and $24 \mathrm{~h}), 4 \%$ paraformaldehyde was used to fix the cells, which then treated with Immunol staining blocking buffer for blocking. Briefly, the NPC cells were incubated with primary and secondary antibodies. Finally, nuclei were counter-staining with DAPI solution, and coverslips were mounted with Antifade polyvinylpyrrolidone mounting medium. The EVOS FL Auto microscope (Life technologies, USA) was used to take images, and the number of cells which expressed the target proteins in the cytoplasm and nucleus were counted.

\section{Co-immunoprecipitation(Co-IP)}

The proteins of the vector group and the VEGF group were extracted separately, and the specific steps are as described above. $40 \mu \mathrm{L}$ of Anti-Flag ${ }^{\circledR} \mathrm{M} 2$ Affinity Gel was thoroughly mixed with $1 \mathrm{~mL}$ PBS, centrifuged and discarded the supernatant. $500 \mu \mathrm{L}$ of total proteins were mixed with the above precipitate, and then incubated them overnight at $4^{\circ} \mathrm{C}$. Subsequently, the mixture was centrifuged again and discarded the supernatant. $4 \times$ SDS-PAGE binding buffer were put into the precipitate and denatured by heating at $100^{\circ} \mathrm{C}$. Then, the next steps of gel electrophoresis were the same as that of western blot analysis.

\section{In vivo nude mouse models}

Male athymic 4-week-old BALB/C nude mice were housed under specific pathogen free (SPF) conditions in Experimental Animal Center of Guangxi Medical University. Two group cells $\left(4 \times 10^{6}\right)$ were implanted into the right groin of nude mice. There are 6 mice in each group, and each mouse is marked with an ear tag. When the tumor diameter was about $1 \mathrm{~cm}, 3$ mice from each group were randomly selected for $8 \mathrm{~Gy}$ irradiation. All mice were sacrificed after observation for about 12 days after irradiation. During the periodical measurement of tumor size, calculate tumor volume according to the following formula: $\mathrm{V}=$ width ${ }^{2} \times$ length $\times 0.5$. Tumor tissues were submerged in formalin for hematoxylin and eosin (H\&E) staining.

\section{Immunohistochemistry (IHC)}

The paraffin-embedded tissue slides were baked in $60^{\circ} \mathrm{C}$ incubator for $2 \mathrm{~h}$, and then dewaxed, hydrated, antigen recovered and the endogenous peroxidase was eliminated. Subsequently, the primary and secondary antibodies were droped on the slides and incubated. The staining intensity was recorded: 0 (no staining), 1 (light yellow), 2 (yellow), 3 (brownish yellow). The percentage of stained cells was recorded: 1 (0-25\%), 2 (26\%-50\%), 3 (51\%-75\%) and 4 (76\%-100\%). Then multiply the score of staining intensity and percentage stained cells to get the immunoreactivity score of each tissue, and it was classified into two grades: low (0-3) or high (4-7).

\section{TUNEL}

TUNEL assay was detected with the commercial Tunel kit (Roche, Basel, Switzerland) according to the instruction of manufacture. The tunel-positive cells were regarded as apoptotic cells by observing the 
sections on the fluorescence microscope (EVOS FL Auto) and analyzing five randomly selected regions of each slide. The apoptotic index was calculated as a percentage of apoptotic nuclei to total nuclei.

\section{Statistical Analysis}

All statistical results were analyzed using SPSS 17.0 and GraphPad Prism 5.0 softwares. All data are expressed as means \pm standard deviation. Statistical $p$ values were analyzed by Students' $t$ tests or oneway ANOVAs. $P<0.05$ was supposed to indicate statistical significance. Each experiment was repeated three times.

\section{Results}

\section{VEGF expression is associated with radiosensitivity in radioresistant nasopharyngeal cancer cell}

Our team has established radioresistant NPC cell CNE-2R derived from the CNE-2 cell. In this experiments, we found that VEGF expression was significantly higher in CNE-2R cells than that in CNE-2 cells (Fig.1a and $b$ ). Therefore, we suspected that VEGF is necessary for radioresistance in NPC cells. To test this conjecture, we silenced VEGF with two different shRNAs, which sequences was 5'-

GCGCAGCTACTGCCATCCAAT-3' and 5'-CACAACAAATGTGAATGCAGA-3', the negative control scramble sequence was TTCTCCGAACGTGTCACGT. As shown in Fig.1c and d, the PCR and western blot results showed we successfully silenced VEGF in CNE-2R cells.

To detect the effect of VEGF on radioresistance, we performed clonogenic assay and CCK-8 assays. The clonogenic assay (Fig.1e and f) revealed VEGF knockdown inhibited cell survival fractions and proliferation under the irradiation, and the radiobiological parameters are shown in Table I. The same results were analyzed using CCK-8 assay (Fig.1g). As expected, these results indicated that VEGF significantly heightened the radioresistance on NPC cells.

\section{VEGF inhibits radiation-induced G2/M cell cycle arrest, apoptosis and DNA breaks.}

Firstly, to further investigate how VEGF inhibits cell growth, we used flow cytometry to assess whether VEGF affects cell cycle progression and apoptosis. Annexin V-APC/7-AAD kit was served to detect the induction of apoptosis. We found that whether $0 \mathrm{~Gy}$ or $8 \mathrm{~Gy}$ was irradiated, VEGF silencing increased the rate of cell apoptosis (Fig.2a and b), and the apoptotic cells were remarkably higher in shRNA groups compared with the NC group $(P<0.05)$. We also found that compared with NC group, given 0 Gy irradiation in shRNA groups caused a slight accumulation of cells in $G 2 / M$ phase $(P<0.05)$, and after given $8 \mathrm{~Gy}$ irradiation in shRNA groups the proportion of G2/M phase was remarkably increased $(P<0.05)$ (Fig.2c-e). This result demonstrated VEGF silencing can induce cell cycle arrest.

To detect the influence of VEGF on DNA repair and damage capacity, we quantified $\mathrm{\gamma}-\mathrm{H} 2 \mathrm{AX}$ foci formation in NC and shRNA groups at different time points $(0,2,4,6,12,24 \mathrm{~h})$ after 8 Gy irradiation by immunofluorescence staining. As expected, the peak foci value appeared in NC and shRNA groups at $4 \mathrm{~h}$ after 8 Gy irradiation, which was gradually decreased to the basic level at $24 \mathrm{~h}$ after 8 Gy irradiation. In 
addition, inhibition of VEGF induced a remarkable increase in residual DNA damage and DNA damge existed to some extent at $24 \mathrm{~h}$ (Fig.3a and b). The results indicated that the repair of DNA damage was repressed by VEGF-silenced NPC cells, which was manifested by the persistence of $\mathrm{y}-\mathrm{H} 2 \mathrm{AX}$ foci from $4 \mathrm{~h}$ to $24 \mathrm{~h}$ after irradiation.

\section{Silencing VEGF can inhibit autophagy induced by irradiation}

Firstly, we employed western blot to investigate the effect of VEGF on autophagy-related proteins without irradiation. The expression of p62 was decreased and LC3 II was increased in shRNA cells compared with NC cells (Fig.4a). The results showed that VEGF silencing inhibited the autophagy-related proteins in NPC cells. To further explore whether VEGF influenced the activity of autophagy induced by irradiation, western blot and immunofluorescence staining were utilized to observe autophagic activity in NC and shRNA groups at different time points $(0,2,4,6,12,24 \mathrm{~h})$ after $8 \mathrm{~Gy}$ irradiation. As shown in Fig.4b, the western blot result indicated that LC3 II increased gradually with time and reached peak at $24 \mathrm{~h}$ after 8 Gy irradiation in NC group, p62 declined gradually over the time, however, in shRNA group, the expression level of LC3 II reached peak at $6 \mathrm{~h}$ and p62 was relatively low at $6 \mathrm{~h}$ after 8Gy irradiation. Meanwhile,we employed immunofluorescence assay to detect the formation of LC3 II puncta in NPC cells. After 8 Gy irradiation, the number of LC3 II puncta in NC cells increased significantly at $24 \mathrm{~h}$, while that in shRNA cells increased significantly at $6 \mathrm{~h}$ (Fig.4c and d). Overall, these results showed that VEGF knockdown inhibited radiation-induced autophagy in NPC cells.

\section{VEGF regulates autophagy through the mTOR pathway}

It is well known that mTOR is related to autophagy, so we further explored whether VEGF regulates autophagy through mTOR pathway in NPC cell. First of all, we used western blotting to confirm that phosphorylated mTOR declined significantly after silencing VEGF, whereas total mTOR protein remained almost unchanged (Fig.5a). In order to further verify the correlation between VEGF and MTOR, we overexpressed VEGF in CNE-2R cells (Fig.5c and d). We then used Co-IP assay to confirm that VEGF precipitate down together with mTOR (Fig. 5e), which indicated that VEGF interacted with mTOR. Fig.5b showed that autophagy were suppressed by given the mTOR activator (MHY1485) to CNE-2R cells, and autophagy were increased after given the mTOR inhibitor (Rapamycin). The above findings demonstrated that VEGF konckdown inhibited the autophagy by activating the mTOR pathway in NPC cells.

\section{VEGF can regulate autophagy to enhance radioresistance in vivo}

Our in vitro studies verified that VEGF can affect radiosensitivity of nasopharyngeal carcinoma by regulating autophagy. To further investigate these effects in vivo, VEGF-silenced cells were injected into nude mice. Half of the nude mice in shRNA group and NC group were randomly selected for $8 \mathrm{~Gy}$ irradiation on the 15th day. We found that inhibition of VEGF significantly repressed tumor growth with or without irradiation (Fig.6a and b). No matter what given 0 Gy or 8 Gy irradiation, the IHC assays confirmed that LC3 II and VEGF expression were much higher in NC group than that in shRNA group, and p62 expression was exactly the opposite (Fig.6c). The percentages of apoptotic cells were tested by 
TUNEL staining in tumor sections (Fig.6d and e). Compared with the NC cells, the apoptosis level of the shRNA cells increased slightly at 0 Gy irradiation $(P<0.05)$, by comparison, the apoptosis level was significantly increased in shRNA cells after $8 \mathrm{~Gy}$ irradiation $(P<0.05)$. These results showed that silencing VEGF enhanced the irradiation sensitivity of NPC cells in vivo, which is in keeping with its functions in vitro.

\section{Discussion}

At present, radiotherapy is one of the main treatments for NPC. However, during the treatment course, treatment failure often occurs due to radiation resistance. Therefore, it is particularly important to explore the mechanism of radioresistance in NPC patients. Autophagy is the most common intracellular degradation process in organisms, and it can maintain normal homeostasis and influence tumor development. The anti-stress role of autophagy is important for cancer cell survival during therapy [19, 20]. The radioresistant NPC cell line CNE-2R were highly expressed VEGF as compared to CNE-2 cells. Therefore, this study mainly explored the possible relationships and mechanisms of VEGF and radioresistance in NPC.

Human VEGF gene is located on 6p21.3 chromosome, VEGF has certain bisulfidic bridges in its protein structure [21,22]. Normal angiogenesis is in a dynamically balanced homeostasis, but becomes abnormally active in tumor tissue, and the most important driver of tumor angiogenesis is VEGF [23]. In 1993, Ferrara [24] found that inhibition of VEGF blocked tumor growth. Moreover, knocking down VEGF could significantly inhibit the growth of tumor cells $[25,26]$. Radioresistance is a major obstacle to cancer treatment, and is thought to be involved in multiple signaling pathways in cancer [27]. In 1999, Gorski. found that irradiation increased the secretion of VEGF in tumor cells, and VEGF could also enhance the radioresistance of endothelial cells [28]. Similarly, Chen [29] and Kil [30] found that radiation therapy of tumors induces increased secretion of VEGF. Moreover, the relationship between high VEGF expression in tumor tissues and radiation therapy has been demonstrated in many cancers [31-33]. Consistent with previous reports, our results showed that inhibition of VEGF significantly repressed the tumor growth especially with irradiation, which indicating VEGF could promote the radioresistance in NPC cells.

lonizing radiation-induced cell killing is mainly associated with DNA double-strand breaks (DSB) and cell cycle redistribution. Upon exposure to ionizing radiation, cells produce reactive oxygen species (ROS) and free radicals that induce DNA damage, the most severe being DSB [34]. The cancer cells died of necrosis and apoptosis after irradiation, so radiosensitivity can be measured by the degree of apoptosis cells [35]. Therefore, we demonstrated that CNE-2R cells had a higher apoptotic rate after silencing VEGF especially with irradiation by flow cytometry and TUNEL assays. Since DSBs are the cause of cellular death after irradiation, tumor cells can induce radioresistance by activating DNA repair and cell cycle checkpoints [36]. The $\mathrm{G} 2$ phase of the cell cycle is a late stage of DNA synthesis and numerous proteins are required for mitosis phase [37]. The cell cycle is an important factor of electro-radiation sensitivity and the G2/M phase cells have the highest radiosensitivity. Hence, partial simultaneous radiotherapy of cells during the radiosensitivity phase of the cell cycle is more effective [38]. Cui [39] found that arsenic trioxide enhances 
radiosensitivity by promoting arrest $\mathrm{G} 2 / \mathrm{M}$ phase in esophageal cancer cells, reducing the repair of sublethal damage and inducing apoptosis. In this study, it is confirmed that the G2/M phase of NPC cells was arrested by silencing VEGF. There was a linear correlation between $\mathrm{Y}-\mathrm{H} 2 \mathrm{AX}$ foci and DSBs, the formation and disappearance kinetics of $\mathrm{Y}-\mathrm{H} 2 \mathrm{AX}$ are consistent with the successful repair of DSBs [40]. By IF assay, we observed that $\mathrm{Y}-\mathrm{H} 2 \mathrm{AX}$ expression increased to the maximum about 4 hours after irradiation, and the residual $\mathrm{Y}-\mathrm{H} 2 \mathrm{AX}$ in VEGF-silenced cells lasted for 24 hours. Therefore, these evidence suggested that VEGF silenced could weaken the ability of double-strand DNA repair, which makes tumor cells sensitive to radiation.

In the process of tumor development, autophagy can protect tumor cells from cancer therapy by opposing pressure, providing energy, and regulating homeostasis [41-44]. Furthermore, more and more evidences have confirmed the existence of autophagy is the basic mechanism of cell survival in stressful environments caused by radiotherapy and chemotherapy. The increase of autophagy will enhance the radioresistance of tumor, and tumor with autophagy defect are more sensitive to radiotherapy [45].

The expression of autophagy-related genes light chain 3 (LC3), Beclin-1 and p62 could be used as indicators of tumor recurrence and poor prognosis [46]. The transition from LC3 I to LC3 II is considered to be a sign of autophagy activity. P62 is another marker of autophagy, which known as polypeptide binding protein chelator 1 . When autophagy was inhibited, the expression level of p62 was increased, while when autophagy was induced, the expression level of p62 was decreased [47]. In this experiment, we found that VEGF silencing could inhibit autophagy, and since autophagy is a dynamic process, we measured autophagy-related proteins at different time points after irradiation by western blotting and immunofluorescence. Interestingly, we found that knockdown of VEGF advanced the occurrence of autophagy in NPC cells after irradiation. These results indicated that silencing VEGF can inhibit the autophagy in NPC cells and make them sensitive to radiation.

As we all know, autophagy is regulated by an intricate network, and mTOR pathway has been well characterized. MTOR can be activated to negatively regulate autophagy [48]. Recent studies also show that mTOR pathway is connected with tumor development and treatment resistance [49-51]. In this study, silencing VEGF increased mTOR phosphorylation. Similarly, co-ip assay also confirmed the interconnection between VEGF and mTOR. In addition, we used mTOR activator (MHY1485) and inhibitor (Rapamycin) respectively to evaluate their effects on VEGF-induced autophagy in radioresistant NPC cells. As expected, MHY1485 activated the expression of p-mTOR and p62, and inhibited the expression of LC3 II in CNE-2R cells, while the effect of rapamycin was the opposite. These findings indicated that silencing VEGF inhibited the autophagy-related proteins by the the activation of mTOR pathway.

\section{Conclusions}

Our research shows that inhibition of VEGF exerts anti-tumor effects and increases the radiosensitivity of NPC cells. In addition, it is evident that the role of VEGF in radioresistance is closely related with the induction of autophagy. We also found that silencing VEGF inhibits autophagy via activating the mTOR 
pathway. Our findings demonstrate that inhibition of VEGF-mediated autophagy may provide a better therapeutic strategy for addressing radioresistance in NPC.

\section{Declarations}

\section{Ethics approval and informed consent}

The animals studies was approved by the Ethics Committee of Guangxi Medical University Cancer Hospital (No. LW2020001).

\section{Funding}

This work was supported by the National Natural Science Foundation of China (Grant No.81760544) ;Youth Science Foundation of Guangxi Medical University (Grant No.GXMUYSF201720);and Middle-aged and Young Teachers' Basic Ability Promotion Project of Guangxi(Grant No.2019KY0115) .

\section{Competing interests}

The authors have no conflict of interest to declare.

\section{Authors' contributions}

$\mathrm{XZ}$ conceived and designed the experiments, LC, GL, KC, FW, YS, RL and XC performed the experiments, $\mathrm{LC}$ and $\mathrm{GL}$ contributed to the data analysis and wrote the manuscript.

\section{Acknowledgements}

Not applicable.

\section{References}

1. Cao SM, Simons MJ, Qian CN. The prevalence and prevention of nasopharyngeal carcinoma in China. Chinese journal of cancer. 2011;30(2):114-9.

2. Feng XP, Yi H, Li MY, Li XH, Yi B, Zhang PF et al. Identification of biomarkers for predicting nasopharyngeal carcinoma response to radiotherapy by proteomics. Cancer research. 2010;70(9):3450-62. doi:10.1158/0008-5472.can-09-4099.

3. Yu L, Chen Y, Tooze SA. Autophagy pathway: Cellular and molecular mechanisms. Autophagy. 2018;14(2):207-15. doi:10.1080/15548627.2017.1378838.

4. Wu Y, Yao J, Xie J, Liu Z, Zhou Y, Pan H et al. The role of autophagy in colitis-associated colorectal cancer. Signal transduction and targeted therapy. 2018;3:31. doi:10.1038/s41392-018-0031-8.

5. Mah LY, Ryan KM. Autophagy and cancer. Cold Spring Harbor perspectives in biology. 2012;4(1):a008821. doi:10.1101/cshperspect.a008821. 
6. Chang L, Graham PH, Hao J, Ni J, Bucci J, Cozzi PJ et al. PI3K/Akt/mTOR pathway inhibitors enhance radiosensitivity in radioresistant prostate cancer cells through inducing apoptosis, reducing autophagy, suppressing NHEJ and HR repair pathways. Cell death \& disease. 2014;5:e1437. doi:10.1038/cddis.2014.415.

7. Yuan X, Du J, Hua S, Zhang H, Gu C, Wang J et al. Suppression of autophagy augments the radiosensitizing effects of STAT3 inhibition on human glioma cells. Experimental cell research. 2015;330(2):267-76. doi:10.1016/j.yexcr.2014.09.006.

8. Liang ZG, Lin GX, Yu BB, Su F, Li L, Qu S et al. The role of autophagy in the radiosensitivity of the radioresistant human nasopharyngeal carcinoma cell line CNE-2R. Cancer management and research. 2018;10:4125-34. doi:10.2147/cmar.s176536.

9. Chu C, Niu X, Ou X and Hu C. LAPTM4B knockdown increases the radiosensitivity of EGFRoverexpressing radioresistant nasopharyngeal cancer cells by inhibiting autophagy. OncoTargets and therapy. 2019;12:5661-77. doi:10.2147/ott.s207810.

10. Cohen-Jonathan Moyal E. [Angiogenic inhibitors and radiotherapy: from the concept to the clinical trial]. Cancer radiotherapie : journal de la Societe francaise de radiotherapie oncologique. 2009;13(67):562-7. doi:10.1016/j.canrad.2009.07.007.

11. Hu L, Sun F, Sun Z, Ni X, Wang J, Wang J et al. Apatinib enhances the radiosensitivity of the esophageal cancer cell line KYSE-150 by inducing apoptosis and cell cycle redistribution. Oncology letters. 2019;17(2):1609-16. doi:10.3892/ol.2018.9803.

12. Stanton MJ, Dutta S, Zhang H, Polavaram NS, Leontovich AA, Honscheid P et al. Autophagy control by the VEGF-C/NRP-2 axis in cancer and its implication for treatment resistance. Cancer research. 2013;73(1):160-71. doi:10.1158/0008-5472.can-11-3635.

13. Y L-R, P C, J M, A B. mTOR Signaling at the Crossroad between Metazoan Regeneration and Human Diseases. International journal of molecular sciences. 2020;21(8). doi:10.3390/ijms21082718.

14. MAA A-B, P X. Molecular regulation of autophagy machinery by mTOR-dependent and -independent pathways. Annals of the New York Academy of Sciences. 2020. doi:10.1111/nyas.14305.

15. $X Y, Y H, Y H, L H, L W, F P$ et al. EG-VEGF silencing inhibits cell proliferation and promotes cell apoptosis in pancreatic carcinoma via PI3K/AKT/mTOR signaling pathway. Biomedicine \& pharmacotherapy = Biomedecine \& pharmacotherapie. 2019;109:762-9. doi:10.1016/j.biopha.2018.10.125.

16. AB P, I T, Z W, TC T. TNF stimulates IL-6, CXCL8 and VEGF secretion from human keratinocytes via activation of mTOR, inhibited by tetramethoxyluteolin. Experimental dermatology. 2018;27(2):135-43. doi:10.1111/exd.13461.

17. Guo Y, Zhu XD, Qu S, Li L, Su F, Li Y et al. Identification of genes involved in radioresistance of nasopharyngeal carcinoma by integrating gene ontology and protein-protein interaction networks. International journal of oncology. 2012;40(1):85-92. doi:10.3892/ijo.2011.1172.

18. Zhou ZR, Zhu XD, Zhao W, Qu S, Su F, Huang ST et al. Poly(ADP-ribose) polymerase-1 regulates the mechanism of irradiation-induced CNE-2 human nasopharyngeal carcinoma cell autophagy and 
inhibition of autophagy contributes to the radiation sensitization of CNE-2 cells. Oncology reports. 2013;29(6):2498-506. doi:10.3892/or.2013.2382.

19. Maycotte P, Thorburn A. Autophagy and cancer therapy. Cancer biology \& therapy. 2011;11(2):12737.

20. Klionsky DJ, Emr SD. Autophagy as a regulated pathway of cellular degradation. Science (New York, NY). 2000;290(5497):1717-21.

21. Yamazaki Y, Morita T. Molecular and functional diversity of vascular endothelial growth factors. Molecular diversity. 2006;10(4):515-27. doi:10.1007/s11030-006-9027-3.

22. Takahashi H, Shibuya M. The vascular endothelial growth factor (VEGF)/VEGF receptor system and its role under physiological and pathological conditions. Clinical science (London, England : 1979). 2005;109(3):227-41. doi:10.1042/cs20040370.

23. Hicklin DJ, Ellis LM. Role of the vascular endothelial growth factor pathway in tumor growth and angiogenesis. Journal of clinical oncology : official journal of the American Society of Clinical Oncology. 2005;23(5):1011-27. doi:10.1200/jco.2005.06.081.

24. Ferrara N. From the discovery of vascular endothelial growth factor to the introduction of avastin in clinical trials - an interview with Napoleone Ferrara by Domenico Ribatti. The International journal of developmental biology. 2011;55(4-5):383-8. doi:10.1387/ijdb.103216dr.

25. Luo M, Hou L, Li J, Shao S, Huang S, Meng D et al. VEGF/NRP-1axis promotes progression of breast cancer via enhancement of epithelial-mesenchymal transition and activation of NF-kappaB and betacatenin. Cancer letters. 2016;373(1):1-11. doi:10.1016/j.canlet.2016.01.010.

26. Jendreyko N, Popkov M, Rader C, Barbas CF, 3rd. Phenotypic knockout of VEGF-R2 and Tie-2 with an intradiabody reduces tumor growth and angiogenesis in vivo. Proceedings of the National Academy of Sciences of the United States of America. 2005;102(23):8293-8. doi:10.1073/pnas.0503168102.

27. Yang L, Liu L, Xu Z, Liao W, Feng D, Dong X et al. EBV-LMP1 targeted DNAzyme enhances radiosensitivity by inhibiting tumor angiogenesis via the JNKs/HIF-1 pathway in nasopharyngeal carcinoma. Oncotarget. 2015;6(8):5804-17. doi:10.18632/oncotarget.3331.

28. Gorski DH, Beckett MA, Jaskowiak NT, Calvin DP, Mauceri HJ, Salloum RM et al. Blockage of the vascular endothelial growth factor stress response increases the antitumor effects of ionizing radiation. Cancer research. 1999;59(14):3374-8.

29. Chen YH, Pan SL, Wang JC, Kuo SH, Cheng JC, Teng CM. Radiation-induced VEGF-C expression and endothelial cell proliferation in lung cancer. Strahlentherapie und Onkologie : Organ der Deutschen Rontgengesellschaft [et al]. 2014;190(12):1154-62. doi:10.1007/s00066-014-0708-z.

30. Kil WJ, Tofilon PJ, Camphausen K. Post-radiation increase in VEGF enhances glioma cell motility in vitro. Radiation oncology (London, England). 2012;7:25. doi:10.1186/1748-717x-7-25.

31. Park I, Yang H, Park JS, Koh GY, Choi EK. VEGF-Grab Enhances the Efficacy of Radiation Therapy by Blocking VEGF-A and Treatment-Induced PIGF. International journal of radiation oncology, biology, physics. 2018;102(3):609-18. doi:10.1016/j.jijrobp.2018.06.401. 
32. Zhang N, Gao X, Zhao Y, Datta M, Liu P, Xu L. Rationally combining anti-VEGF therapy with radiation in NF2 schwannoma. Journal of rare diseases research \& treatment. 2016;1(2):51-5.

33. Gao X, Zhao Y, Stemmer-Rachamimov AO, Liu H, Huang P, Chin S et al. Anti-VEGF treatment improves neurological function and augments radiation response in NF2 schwannoma model. Proceedings of the National Academy of Sciences of the United States of America. 2015;112(47):14676-81. doi:10.1073/pnas.1512570112.

34. Roos WP, Kaina B. DNA damage-induced cell death: from specific DNA lesions to the DNA damage response and apoptosis. Cancer letters. 2013;332(2):237-48. doi:10.1016/j.canlet.2012.01.007.

35. Rahmanian N, Hosseinimehr SJ, Khalaj A. The paradox role of caspase cascade in ionizing radiation therapy. Journal of biomedical science. 2016;23(1):88. doi:10.1186/s12929-016-0306-8.

36. Morgan MA, Lawrence TS. Molecular Pathways: Overcoming Radiation Resistance by Targeting DNA Damage Response Pathways. Clinical cancer research : an official journal of the American Association for Cancer Research. 2015;21(13):2898-904. doi:10.1158/1078-0432.ccr-13-3229.

37. Hartwell LH, Weinert TA. Checkpoints: controls that ensure the order of cell cycle events. Science (New York, NY). 1989;246(4930):629-34.

38. Pawlik TM, Keyomarsi K. Role of cell cycle in mediating sensitivity to radiotherapy. International journal of radiation oncology, biology, physics. 2004;59(4):928-42. doi:10.1016/j.ijrobp.2004.03.005.

39. Cui YH, Liang HJ, Zhang QQ, Li SQ, Li XR, Huo XQ et al. Radiosensitivity enhancement by arsenic trioxide in conjunction with hyperthermia in the EC-1 esophageal carcinoma cell line. Asian Pacific journal of cancer prevention : APJCP. 2012;13(4):1693-7.

40. BanáthJP, Macphail SH, Olive PL. Radiation sensitivity, H2AX phosphorylation, and kinetics of repair of DNA strand breaks in irradiated cervical cancer cell lines. Cancer research. 2004;64(19):7144-9. doi:10.1158/0008-5472.can-04-1433.

41. Hait WN, Jin S, Yang JM. A matter of life or death (or both): understanding autophagy in cancer. Clinical cancer research : an official journal of the American Association for Cancer Research. 2006;12(7 Pt 1):1961-5. doi:10.1158/1078-0432.ccr-06-0011.

42. Zhou S, Zhao L, Kuang M, Zhang B, Liang Z, Yi T et al. Autophagy in tumorigenesis and cancer therapy: Dr. Jekyll or Mr. Hyde? Cancer letters. 2012;323(2):115-27. doi:10.1016/j.canlet.2012.02.017.

43. Mathew R, Karp CM, Beaudoin B, Vuong N, Chen G, Chen HY et al. Autophagy suppresses tumorigenesis through elimination of p62. Cell. 2009;137(6):1062-75. doi:10.1016/j.cell.2009.03.048.

44. Singh SS, Vats S, Chia AY, Tan TZ, Deng S, Ong MS et al. Dual role of autophagy in hallmarks of cancer. Oncogene. 2018;37(9):1142-58. doi:10.1038/s41388-017-0046-6.

45. Wang F, Tang J, Li P, Si S, Yu H, Yang X et al. Chloroquine Enhances the Radiosensitivity of Bladder Cancer Cells by Inhibiting Autophagy and Activating Apoptosis. Cellular physiology and biochemistry : international journal of experimental cellular physiology, biochemistry, and pharmacology. 2018;45(1):54-66. doi:10.1159/000486222. 
46. Terabe T, Uchida F, Nagai H, Omori S, Ishibashi-Kanno N, Hasegawa S et al. Expression of autophagyrelated markers at the surgical margin of oral squamous cell carcinoma correlates with poor prognosis and tumor recurrence. Human pathology. 2018;73:156-63. doi:10.1016/j.humpath.2017.11.019.

47. Pankiv S1, Clausen TH, Lamark T, Brech A, Bruun JA, Outzen H et al. p62/SQSTM1 binds directly to Atg8/LC3 to facilitate degradation of ubiquitinated protein aggregates by autophagy. The Journal of biological chemistry. 2007;282(33):24131-45. doi:10.1074/jbc.M702824200.

48. Zhang Y, Fan Y, Huang S, Wang G, Han R, Lei F et al. Thymoquinone inhibits the metastasis of renal cell cancer cells by inducing autophagy via AMPK/mTOR signaling pathway. Cancer science. 2018;109(12):3865-73. doi:10.1111/cas.13808.

49. Yin C, Ke X, Zhang R, Hou J, Dong Z, Wang F et al. G9a promotes cell proliferation and suppresses autophagy in gastric cancer by directly activating mTOR. FASEB journal : official publication of the Federation of American Societies for Experimental Biology. 2019;33(12):14036-50. doi:10.1096/fj.201900233RR.

50. Luan W, Pang Y, Li R, Wei X, Jiao X, Shi J et al. Akt/mTOR-Mediated Autophagy Confers Resistance To BET Inhibitor JQ1 In Ovarian Cancer. OncoTargets and therapy. 2019;12:8063-74. doi:10.2147/ott.s220267.

51. Wang LL, Zhang L, Cui XF. viaDownregulation of long noncoding RNA LINC01419 inhibits cell migration, invasion, and tumor growth and promotes autophagy inactivation of the PI3K/Akt1/mTOR pathway in gastric cancer. Therapeutic advances in medical oncology. 2019;11:1758835919874651. doi:10.1177/1758835919874651

\section{Table}

Table I. Radiobiological parameters of the three groups (Mean \pm SD)

\begin{tabular}{llll} 
Cell lines & $\mathrm{D}_{0}$ & $\mathrm{Dq}$ & $\mathrm{SF}_{2}$ \\
\hline $\mathrm{NC}$ & $5.091 \pm 0.178$ & $2.362 \pm 0.309$ & $0.787 \pm 0.008$ \\
\hline ShRNA1 & $4.31 \pm 0.391$ & $1.667 \pm 0.026$ & $0.724 \pm 0.008$ \\
\hline ShRNA2 & $4.193 \pm 0.189$ & $1.465 \pm 0.083$ & $0.735 \pm 0.008$ \\
\hline$p$ & 0.082 & $<0.05$ & $<0.05$
\end{tabular}

$D_{0}$ is the average lethal dose, which is the dose required to hit each cell once. $\mathrm{Dq}$ is a quasi-threshold dose, which refers to the ability to repair sublethal injury. $\mathrm{SF}_{2}$ is the survival fraction at 2 Gy radiation dose.

\section{Figures}


a

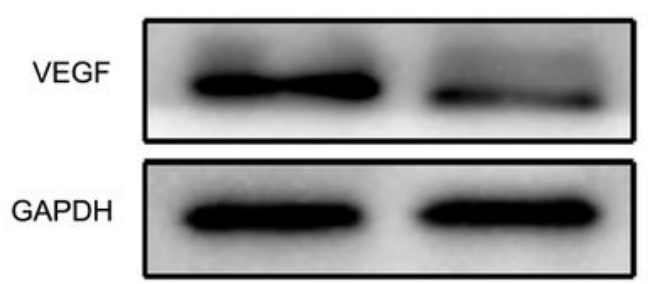

CNE-2R

c

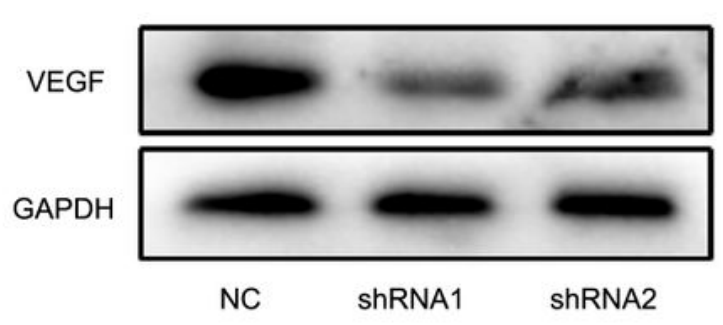

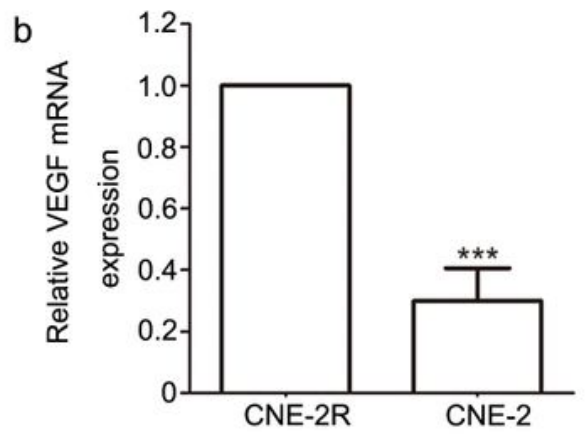

d

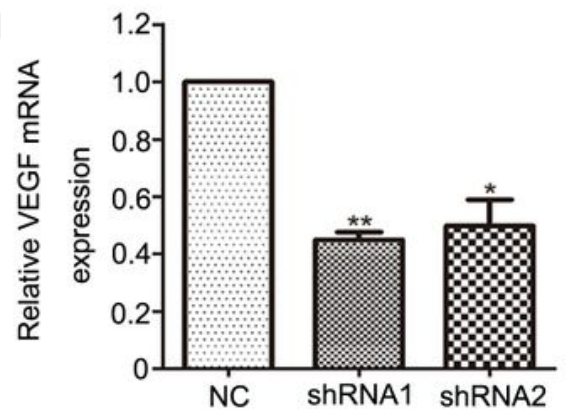

e

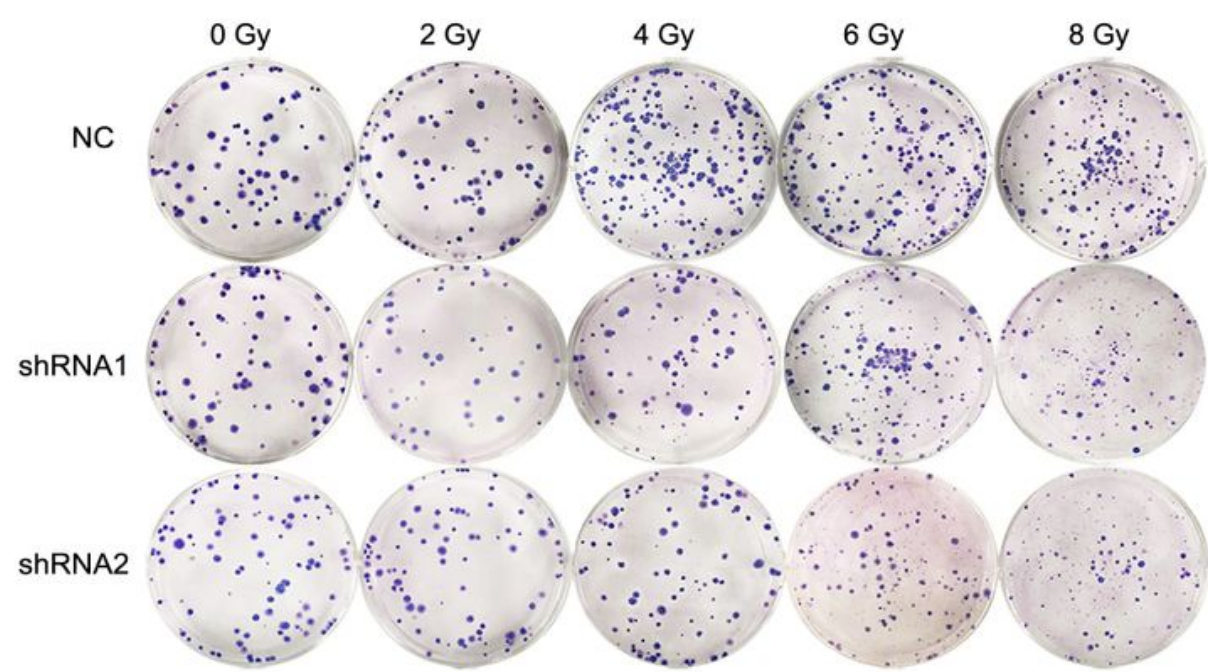

f

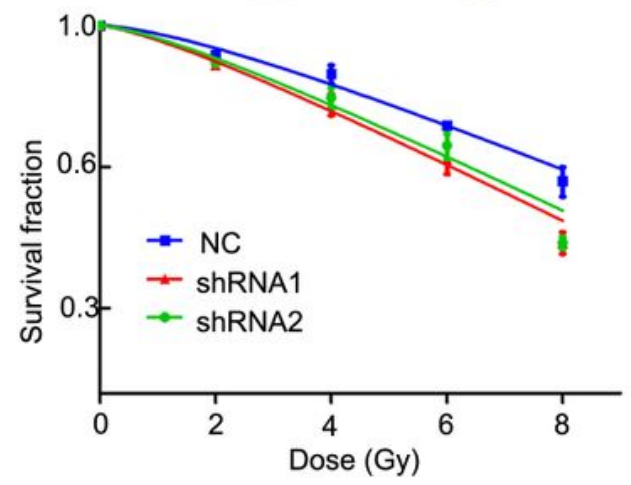

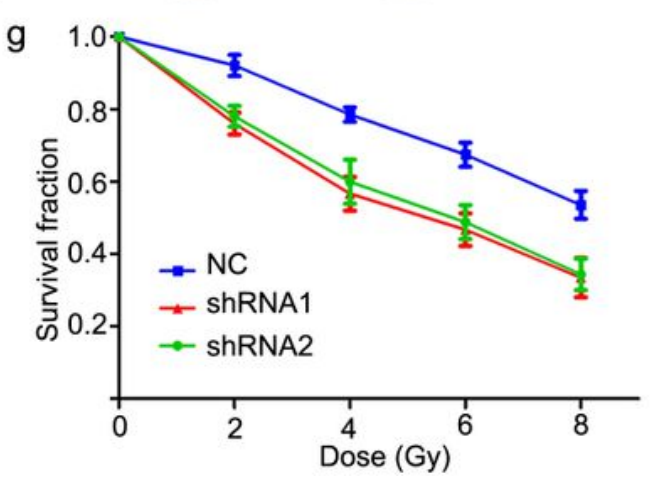

\section{Figure 1}

Effect of VEGF on radiosensitivity of nasopharyngeal carcinoma cells. $(a, b)$ The expression of VEGF protein and mRNA in CNE-2R and CNE-2 cells. ${ }^{\star * \star} p<0.001$, CNE-2 versus CNE-2R. (c, d). The expression of VEGF protein and mRNA in CNE-2R cells treated with control or VEGF short hairpin RNAs (shRNAs). (e, $\mathrm{f}$ ) The number of colonies and the size of the colonies were analyzed in NC and shRNAs cells after 
irradiation. (g) Cell proliferation in NC and shRNAs cells were detected by CCK-8 assay after irradiation. * $p<0.05, * * p<0.01$ and $* * * p<0.001$, shRNAs versus NC.

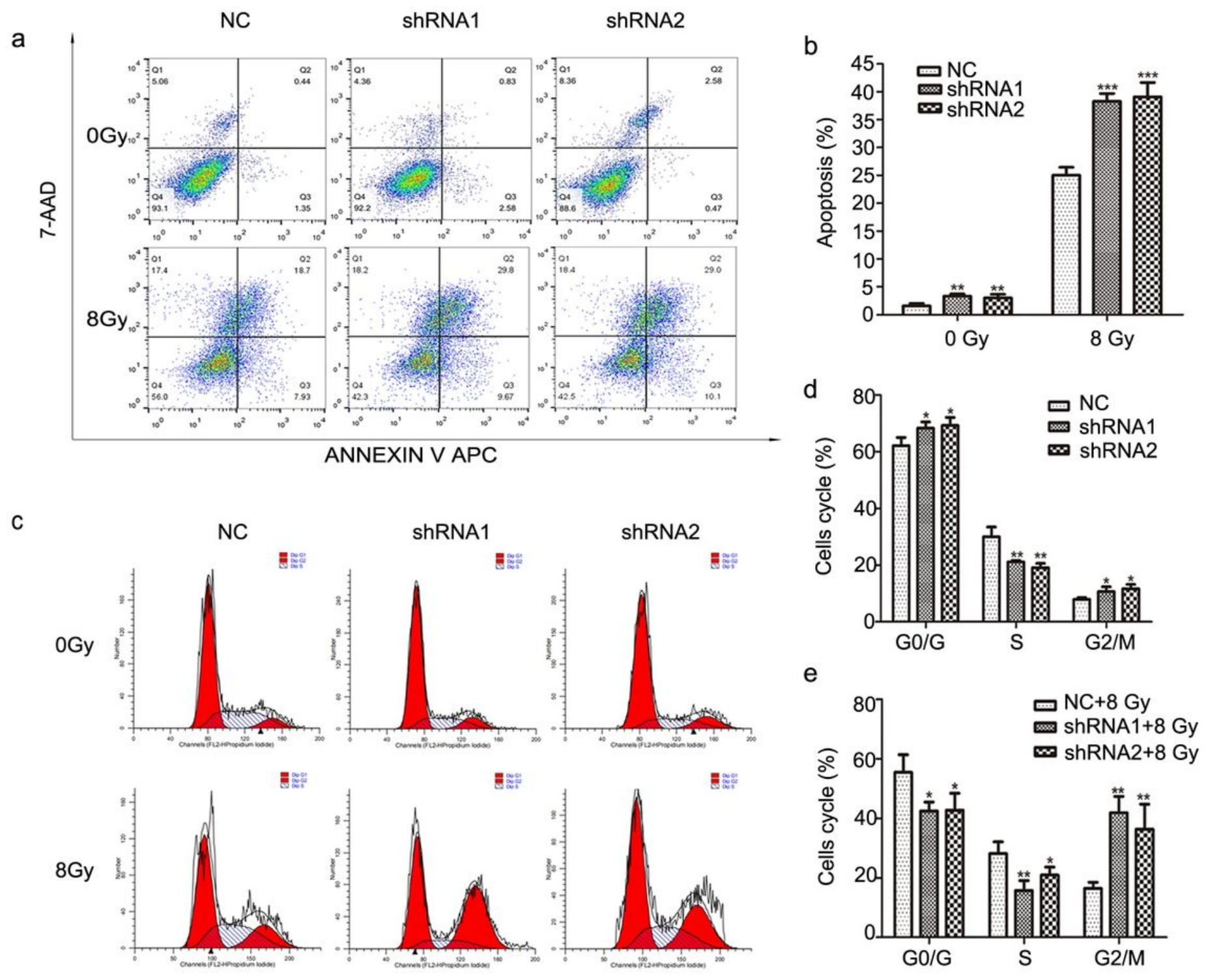

Figure 2

Silencing VEGF increased radiation-induced apoptosis and G2/M cell cycle arrest. (a,b) Flow cytometry was used to detect cell apoptosis in NC and shRNAs cells with or without $8 \mathrm{~Gy}$ irradiation. (c-e) The cell cycle in NC and shRNAs cells were subjected to flow cytometry with or without 8 Gy irradiation. * $p<0.05$, ${ }^{* *} p<0.01$ and ${ }^{* *} p<0.001$, shRNAs versus NC. 

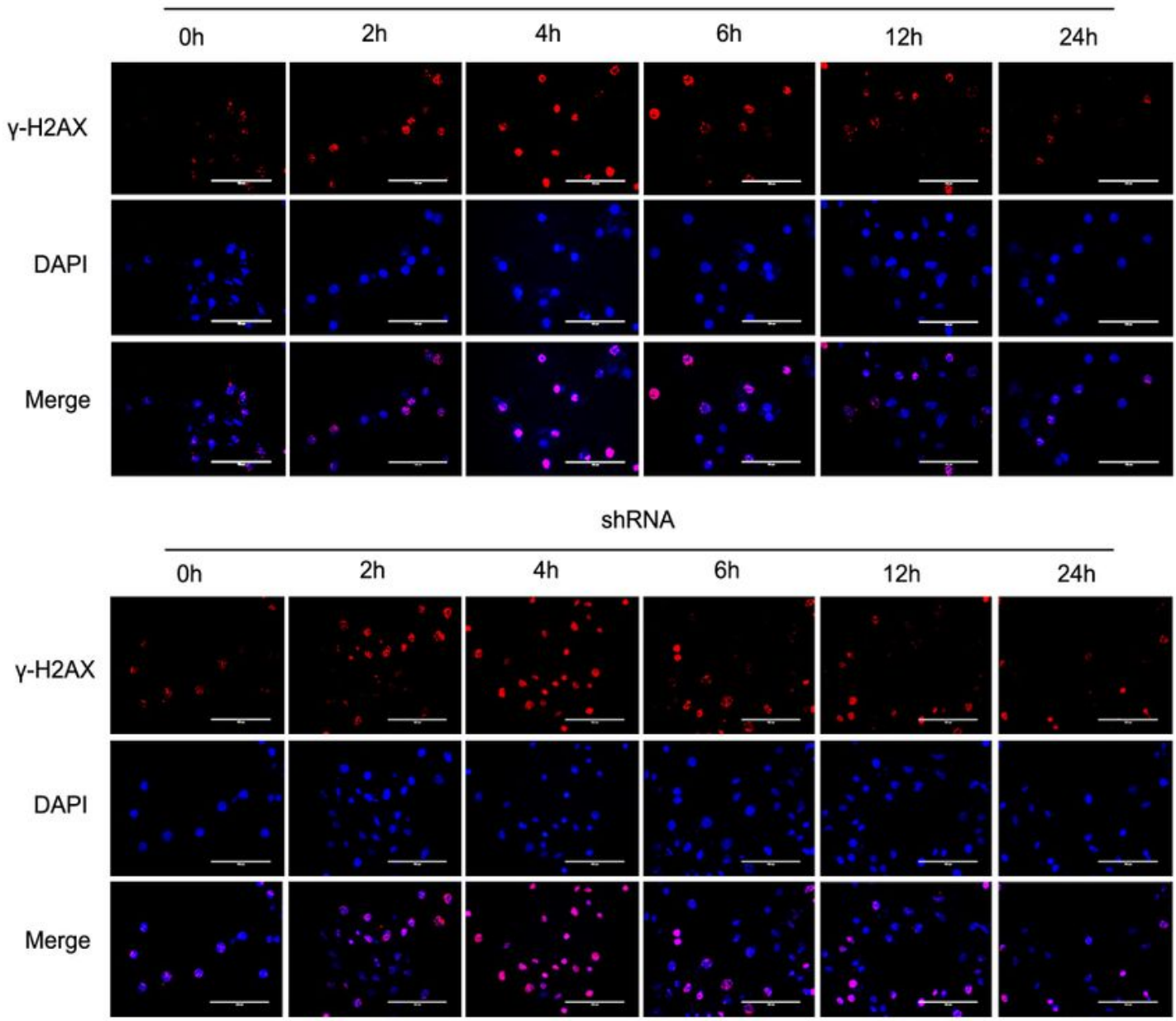

b

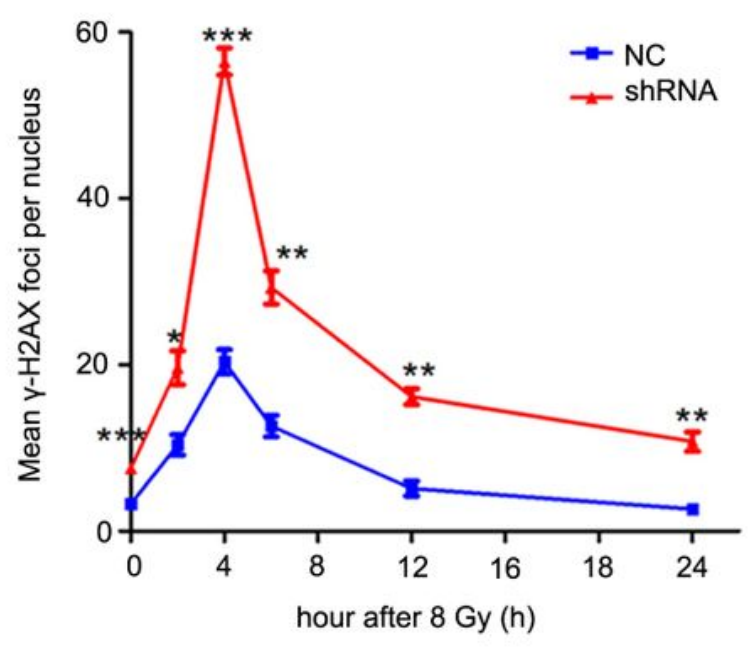

\section{Figure 3}

Silencing VEGF decreased DNA damage repair in CNE-2R cells. (a) Immunofluorescence for $\mathrm{Y}-\mathrm{H} 2 \mathrm{AX}$ at different time point after $8 \mathrm{~Gy}$ irradiation in NC and shRNA cells. (b) The statistical result of mean $\mathrm{y}-\mathrm{H} 2 \mathrm{AX}$ foci per nucleus in NC and shRNA cells. ${ }^{*} p<0.05,{ }^{* \star} p<0.01$ and ${ }^{* \star *} p<0.001$, shRNA versus NC, size bars $=100 \mu \mathrm{m}$. 
a

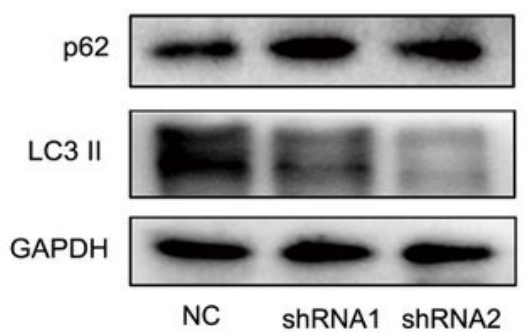

b

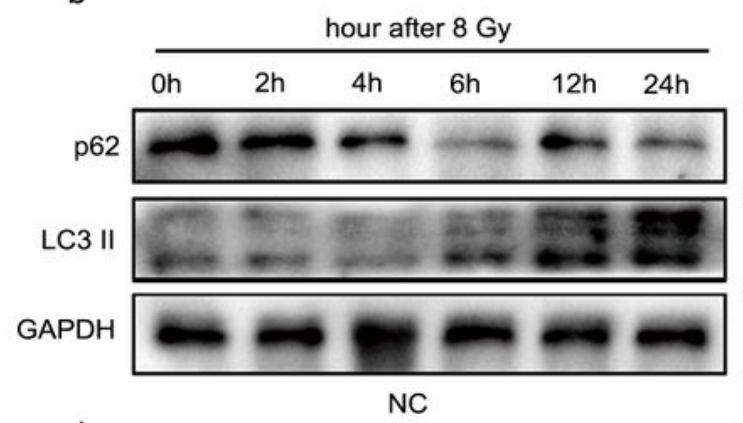

d

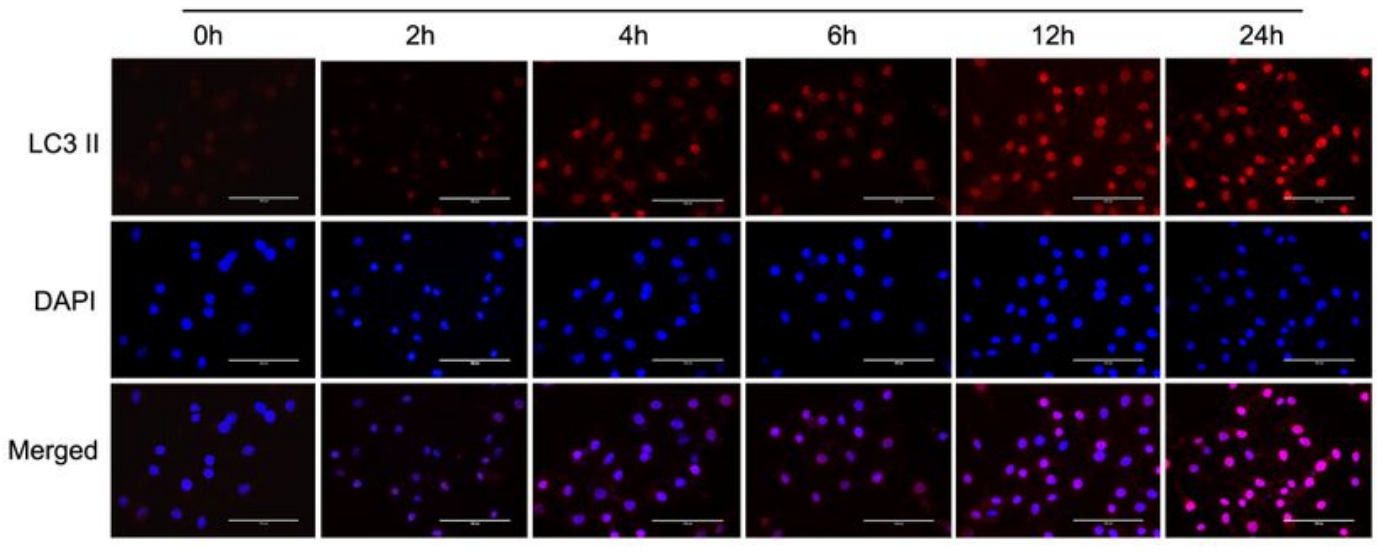

ShRNA

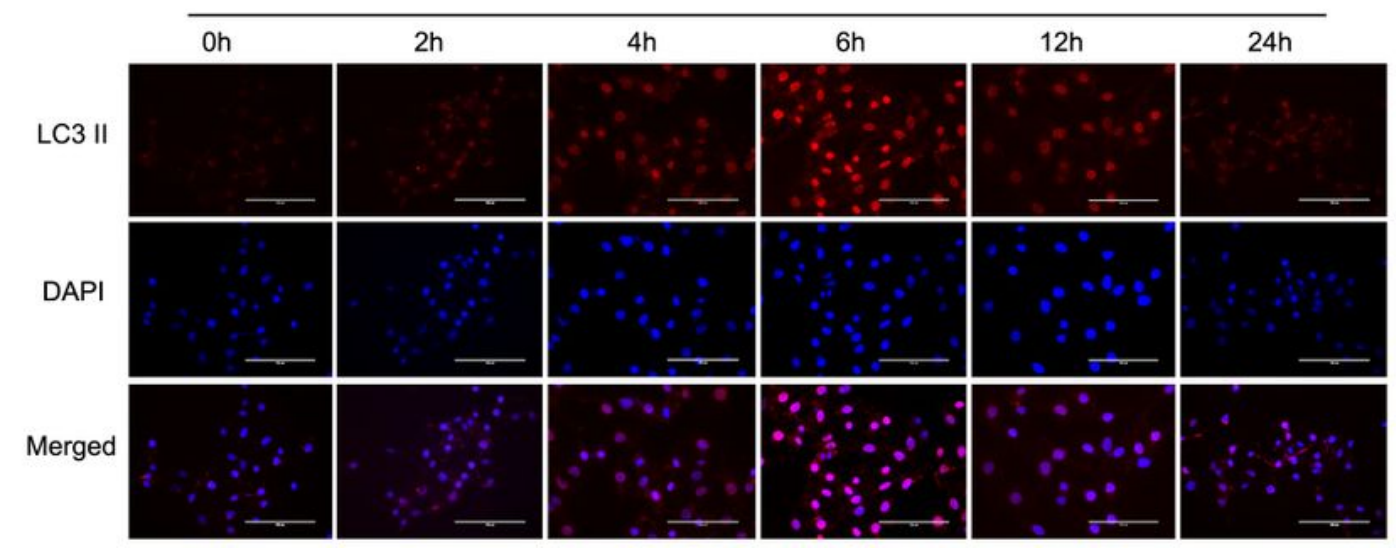

\section{Figure 4}

Silencing VEGF inhibited radiation-induced autophagy. (a) The expression of p62 and LC3 II proteins in NC and shRNAs cells. (b)The expression of p62 and LC3 II proteins in NC and shRNA cells at different time point after 8 Gy irradiation. (c) Quantitative analysis of LC3 II protein in immunofluorescence assay. (d) Effect of VEGF on autophagy detected by using immunofluorescence of LC3 II at different time point after 8 Gy irradiation. Size bars $=100 \mu \mathrm{m}$. 
a
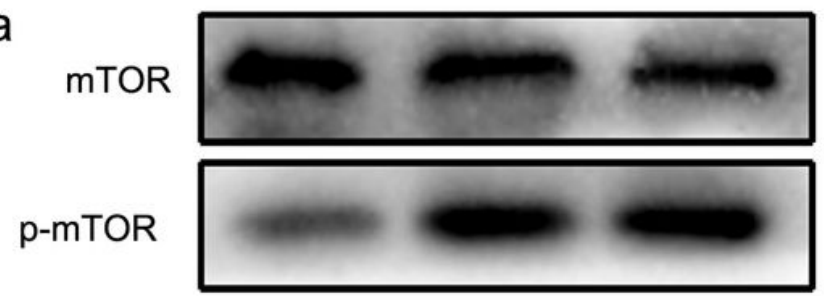

GAPDH

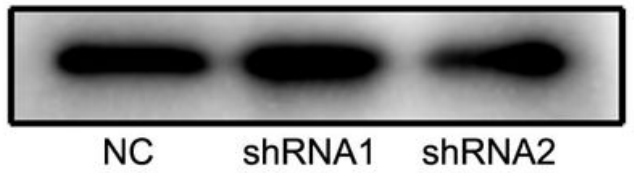

b

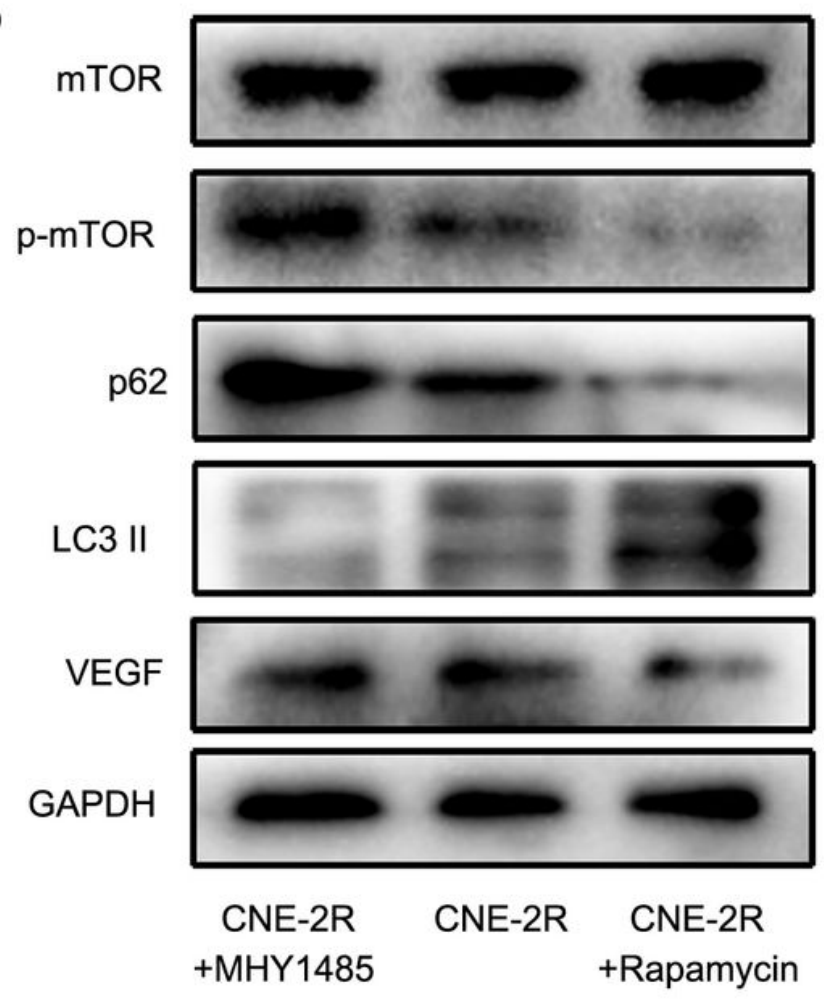

C

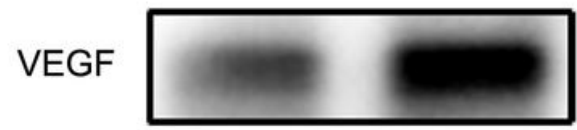

GAPDH

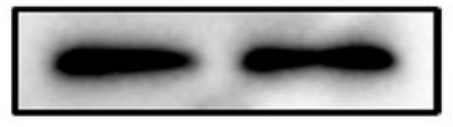

Vector VEGF

d

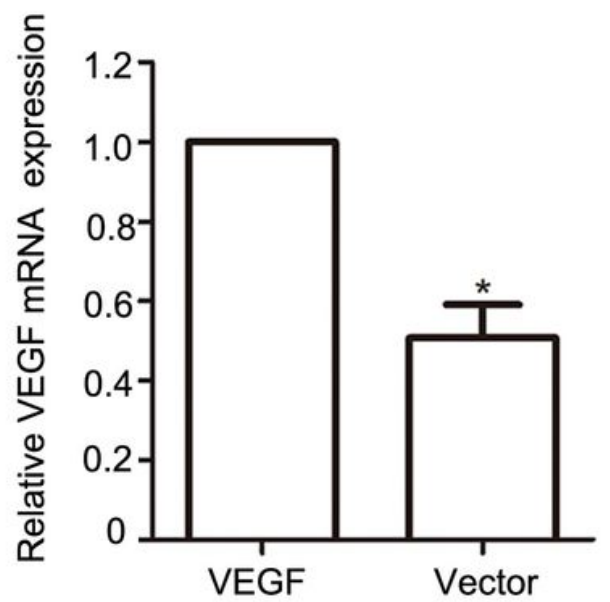

e

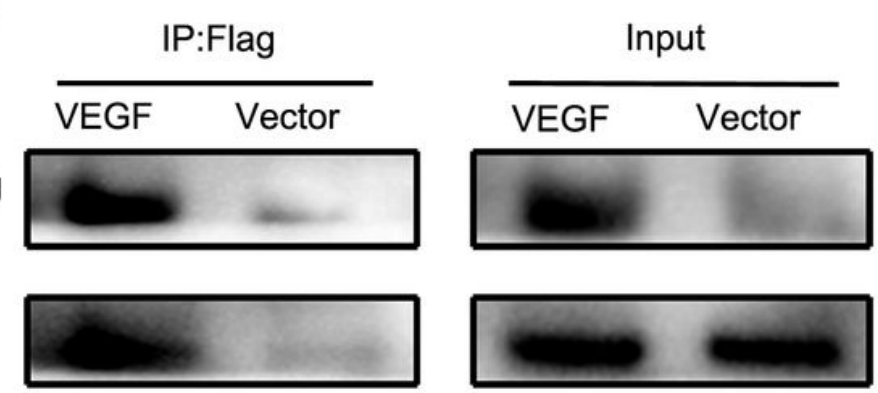

\section{Figure 5}

VEGF regulated autophagy through mTOR pathway. (a) The expression of mTOR and p-mTOR proteins in NC and shRNAs cells. (b) The quantify levels of mTOR, p-mTOR, LC3II, p62 and VEGF was detected by western blotting when mTOR activators (MHY1485) and inhibitors (Rapamycin) were given to CNE-2R cells. (c, d) VEGF overexpression vector was used to transfect into CNE-2R cells . Transfection effociencies were tested by western blotting and qPCR assays. (e) The formation of the VEGF/mTOR complex was detected by Co-IP. 


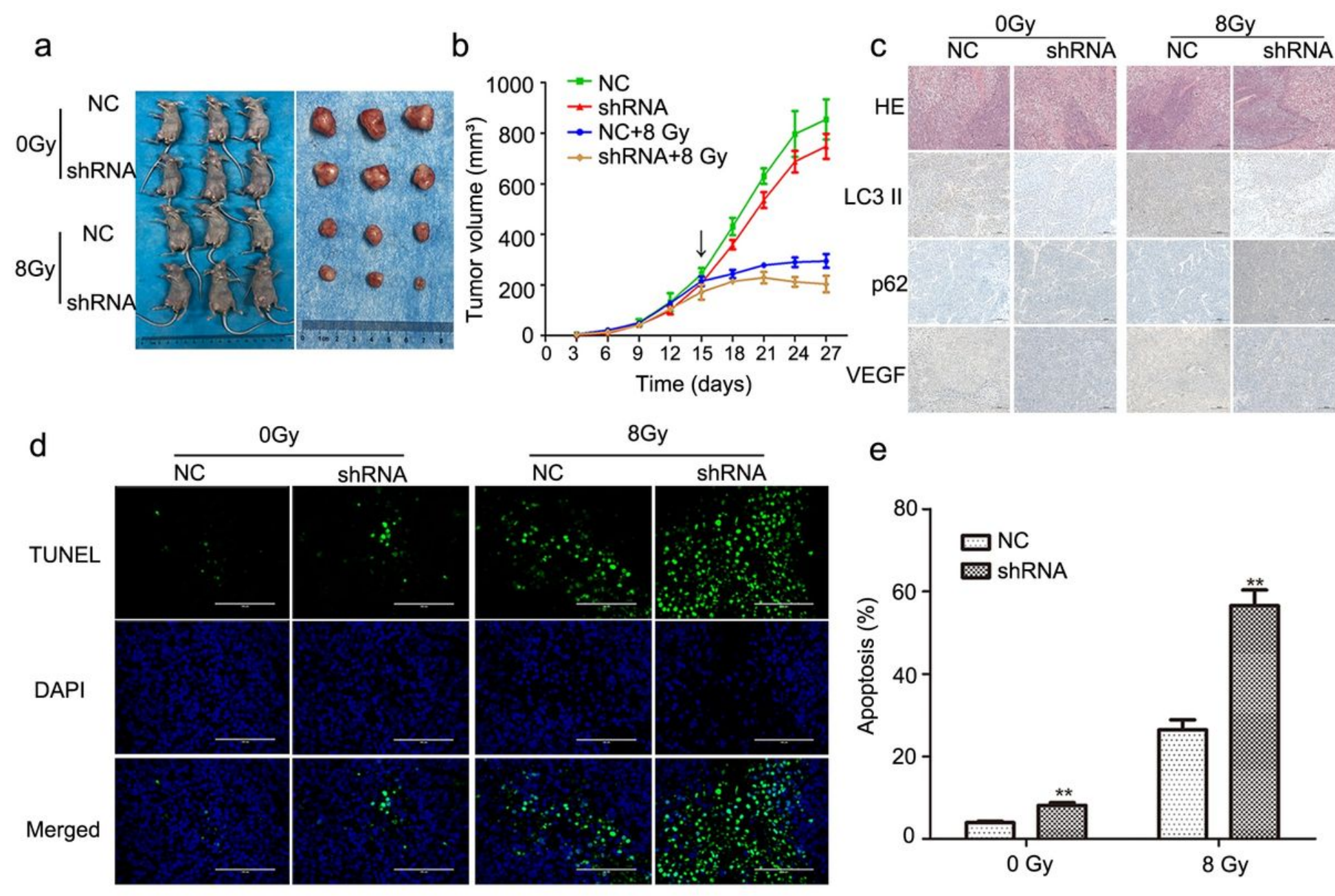

Figure 6

Silencing VEGF promoted the radiosensitivity of nude mouse models. (a) Tumor size of NC and shRNA cells inoculated subcutaneously in nude mice at 27 days. (b) Growth curve of tumor nodules with or without 8 Gy irradiation in each group (black arrow indicates the time point of radiation). (c) Expression of LC3 II, p62 and VEGF was analyzed by IHC assay. (d) Tumor nodules were subjected by TUNEL assay. (e) Quantitative analysis of TUNEL assay results. ${ }^{* \star} p<0.01$, shRNA versus NC, size bars $=100 \mu \mathrm{m}$. 